\title{
Use of secondary stroke prevention medicines in Australia: national trends, 2003-2009
}

\section{Janet K Sluggett BPharm(Hons), GDipClinEpid Research Associatel \\ Gillian E Caughey BSc(Hons), PhD Senior Research Fellow? \\ Michael B Ward \\ BPharm(Hons), PhD Senior Lecturer ${ }^{2}$ \\ Andrew L Gilbert PhD, DipAppPsych, BPharm Emeritus Professor \\ 1 Quality Use of Medicines and Pharmacy Research Centre, Sansom Institute for Health Research University of South Australia, Adelaide, SA. \\ 2 School of Pharmacy and Medical Sciences, University of South Australia, \\ Adelaide, SA. \\ janet.sluggett@ unisa.edu.au}

MJA 2014; 201: 54-57 doi: 10.5694/mjal3.00186 ndividuals diagnosed with transient ischaemic attack (TIA) or ischaemic stroke are at high risk of recurrent vascular events.1,2 Current Australian guidelines recommend continued use of antihypertensive, antithrombotic and lipid-lowering medicines after TIA or ischaemic stroke to reduce the risk of a recurrent ischaemic event, unless contraindications exist. ${ }^{3}$

In Australia, a national audit is conducted every 2 years to assess the quality of acute stroke care, including use of secondary stroke prevention medicines at the time of hospital discharge. ${ }^{4}$ However, few studies have examined use of secondary stroke prevention medicines after discharge from hospital.5,6 Of those available, none have assessed changes in use of these medicines at the national level, and it is unclear whether use has increased since the release of Australia's first stroke management guidelines in 2003. Consequently, the aim of this study was to examine national trends in the use of secondary stroke prevention medicines by TIA and ischaemic stroke survivors to determine whether use has increased over time.

\section{Methods}

A retrospective observational study was conducted using data from the Australian Government Department of Veterans' Affairs (DVA) administrative health claims database. The database contains details of all hospital and pharmaceutical claims subsidised by DVA for Australian veterans and their eligible dependents. At the end of 2009, the treatment population consisted of 263433 veterans. ${ }^{7}$

Patients discharged alive after an episode of care for TIA (identified by International classification of diseases, 10th revision, Australian modification [ICD-10-AM] codes G45.0, G45.1, G45.2, G45.8 and G45.9) or ischaemic stroke (code I63) between 1 January 2000 and 31 December 2009 were eligible for inclusion. They were eligible for subsidisation of all health services

\section{Abstrac}

Objective: To examine recent trends in the use of secondary stroke prevention medicines by transient ischaemic attack (TIA) and ischaemic stroke survivors.

Design, setting and participants: Retrospective observational study of patients aged $\geqslant 65$ years who were hospitalised with a TIA or ischaemic stroke between January 2000 and December 2009. Use of antihypertensive, antithrombotic and lipid-lowering medicines by patients was determined monthly, using claims data from the Australian Government Department of Veterans' Affairs, commencing in January 2003.

Main outcome measure: Monthly prevalence of use of secondary stroke prevention medicines.

Results: Between 2003 and 2009, small increases in use (less than 2\% relative increase annually) were observed for antihypertensive and antithrombotic medicines among 19019 patients. There was a 9\% relative increase in use of lipid-lowering therapy each year. The proportion of patients dispensed all three recommended medicine classes nearly doubled over the 7-year period. By December 2009 , about $80 \%$ of patients were dispensed an antihypertensive, $75 \%$ received an antithrombotic and $60 \%$ were dispensed lipid-lowering therapy. Almost half of the population were dispensed all three recommended classes by the end of the study period.

Conclusions: Increased use of secondary stroke prevention medicines was shown in this study, in accordance with national stroke guideline recommendations and initiatives supporting quality use of medicines in Australia. There may be opportunity to further increase use of these medicines among older Australians who have had a TIA or ischaemic stroke.

by the DVA. We assessed consecutive hospital claims after each TIA or ischaemic stroke claim up to 30 June 2010, as patients may have multiple claims recorded for treatment of the same event. ${ }^{8}$ Data rules established in consultation with clinicians ${ }^{8}$ were used to link stroke-related separations and determine final discharge dates.

The proportion of patients using secondary stroke prevention medicines was determined monthly, commencing in January 2003. Each month, the cohort included all patients aged $\geqslant 65$ years who had had a previous episode of care for TIA or ischaemic stroke recorded between 1 January 2000 and the month under study. Patients with a previous episode of care for both TIA and ischaemic stroke were eligible for inclusion in both cohorts. Patients were included each month until either their death or the end of the study period.

To determine the number of patients dispensed recommended medicines each month, all claims for antihypertensives (identified by the World Health Organization Anatomical Therapeutic Chemical classification codes C02, C03, C07, C08 and C09 [excluding C08EX02, perhexiline]), antithrombotics (code B01A [excluding B01AD, thrombolytics]) and lipid-lowering medicines (code C10) between 1 July 2002 (to include medications taken at, but dispensed before, study commencement) and 31 December 2009 were extracted. As dosage information is not available from the database, prescription durations were used as a measure of duration of use of each medicine. The prescription durations were calculated from the DVA pharmaceutical claims dataset and represent the time in which $75 \%$ of prescriptions for an individual item were refilled. Use of each of the three classes of medicine, combined treatment with antihypertensive and antithrombotic therapy, and treatment with a combination of all three classes of medicine were determined for all patients still living each month.

Prevalence of use each month (January 2003 to December 2009) was age and sex standardised using the DVA population in January 2003 
1 Characteristics of patients who were included at the start and end of the study

\begin{tabular}{lcc} 
Characteristics, by disease cohort & Jan 2003 & Dec 2009 \\
\hline Transient ischaemic attack & & \\
No. of patients & 2765 & 5242 \\
Age (years), median (IQR) & $81.0(78.3-84.4)$ & $86.8(84.1-89.5)$ \\
No. of men (\%) & $1761(63.7 \%)$ & $2716(51.8 \%)$ \\
Time in cohort (years), median (IQR) & $1.3(0.6-2.0)$ & $3.5(1.6-6.1)$ \\
Ischaemic stroke & & \\
No. of patients & 2493 & 4302 \\
Age (years), median (IQR) & $80.9(78.0-84.2)$ & $86.6(84.1-89.2)$ \\
No. of men (\%) & $1609(64.5 \%)$ & $2376(55.2 \%)$ \\
Time in cohort (years), median (IQR) & $1.3(0.6-2.1)$ & $3.3(1.5-5.8)$
\end{tabular}

to account for changes in population characteristics over time. After standardisation, Poisson regression models with generalised estimating equations were used to test for trends in medicine use, using an autoregressive working correlation matrix to adjust for serial correlation. The regression models compared the rate of medicine use in 1 year with the rate in the previous year to test for linear trends between 2003 and 2009. Separate models were used for each treatment and diagnosis combination. All analyses were performed using SAS version 9.4 (SAS Institute).

This study was approved by the University of South Australia and DVA human research ethics committees.

\section{Results}

A total of 19019 patients were included in our analysis. Of these, 403 patients in the cohort was 1.3 years in January 2003 and 3.4 years in December 2009, meaning trends are reflective of use among the prevalent population, rather than among patients with a recent event. Increased use observed in this study suggests practice is moving towards guideline recommendations. Despite this, only half of the population were dispensed medicines from all three recommended classes in December 2009, suggesting there may be opportunity to further increase use of these medicines among the older population.

These findings are consistent with results from international studies conducted within the general practice population over a similar period. $9,10 \mathrm{~A}$ large study from the United Kingdom showed use of antihypertensives in the year after a first stroke increased from approximately $50 \%$ to $70 \%$ between 1999 and 2008, antiplatelet use increased from $60 \%$ to $75 \%$, and use of lipid-lowering therapy increased from $15 \%$ to $80 \% .{ }^{10}$ Large increases in use of lipid-lowering therapy were also shown in a Danish population-based study, with use among ischaemic stroke survivors increasing from $40 \%$ to $65 \%$ between 2004 and 2010.11

Along with the release and dissemination of national stroke guidelines (which were regularly updated during the study period), other quality use of medicines initiatives may have contributed to the increased

2 Changes in use of secondary stroke prevention medicines by transient ischaemic attack and ischaemic stroke survivors between 2003 and 2009

\begin{tabular}{|c|c|c|c|c|c|}
\hline \multirow[b]{2}{*}{ Medicines, by disease cohort } & \multicolumn{2}{|c|}{$\begin{array}{c}\text { Standardised monthly } \\
\text { rate of use (per } 100 \\
\text { patients) }\end{array}$} & \multirow[b]{2}{*}{ Standardised rate ratio $(95 \% \mathrm{Cl})$} & \multirow[b]{2}{*}{$\begin{array}{l}\text { Average annual } \\
\% \text { change }\end{array}$} & \multirow[b]{2}{*}{$P$} \\
\hline & $\operatorname{Jan} 2003$ & Dec 2009 & & & \\
\hline \multicolumn{6}{|l|}{ Transient ischaemic attack } \\
\hline Antihypertensive & 72.5 & 78.2 & $1.016(1.015-1.016)$ & $+1.6 \%$ & $<0.001$ \\
\hline Antithrombotic & 70.4 & 74.0 & $1.013(1.011-1.014)$ & $+1.3 \%$ & $<0.001$ \\
\hline Lipid-lowering & 33.5 & 58.0 & $1.087(1.084-1.091)$ & $+8.7 \%$ & $<0.001$ \\
\hline Antihypertensive + antithrombotic & 55.9 & 63.0 & $1.025(1.023-1.027)$ & $+2.5 \%$ & $<0.001$ \\
\hline $\begin{array}{l}\text { Antihypertensive + antithrombotic + lipid- } \\
\text { lowering }\end{array}$ & 24.4 & 43.0 & 1.094 (1.088-1.101) & $+9.4 \%$ & $<0.001$ \\
\hline \multicolumn{6}{|l|}{ Ischaemic stroke } \\
\hline Antihypertensive & 73.3 & 81.1 & $1.019(1.019-1.020)$ & $+1.9 \%$ & $<0.001$ \\
\hline Antithrombotic & 74.2 & 80.4 & $1.014(1.013-1.015)$ & $+1.4 \%$ & $<0.001$ \\
\hline Lipid-lowering & 36.8 & 64.8 & $1.088(1.087-1.090)$ & $+8.8 \%$ & $<0.001$ \\
\hline Antihypertensive + antithrombotic & 59.4 & 70.2 & $1.027(1.025-1.028)$ & $+2.7 \%$ & $<0.001$ \\
\hline $\begin{array}{l}\text { Antihypertensive + antithrombotic + lipid- } \\
\text { lowering }\end{array}$ & 26.9 & 52.3 & $1.102(1.098-1.106)$ & $+10.2 \%$ & $<0.001$ \\
\hline
\end{tabular}


3 Trends in monthly use of secondary stroke prevention medicines by patients previously hospitalised with a transient ischaemic attack or ischaemic stroke

A: Transient ischaemic attack

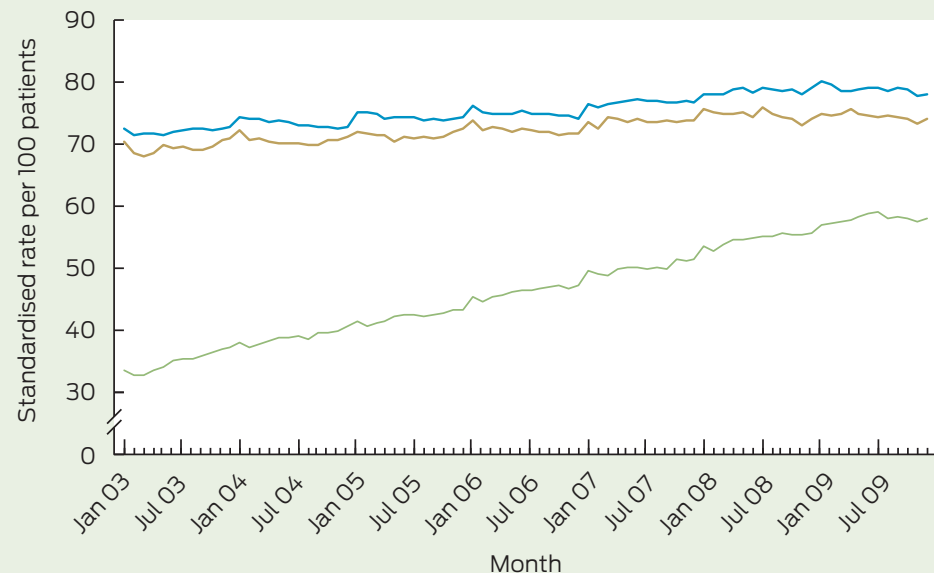

B: Ischaemic stroke

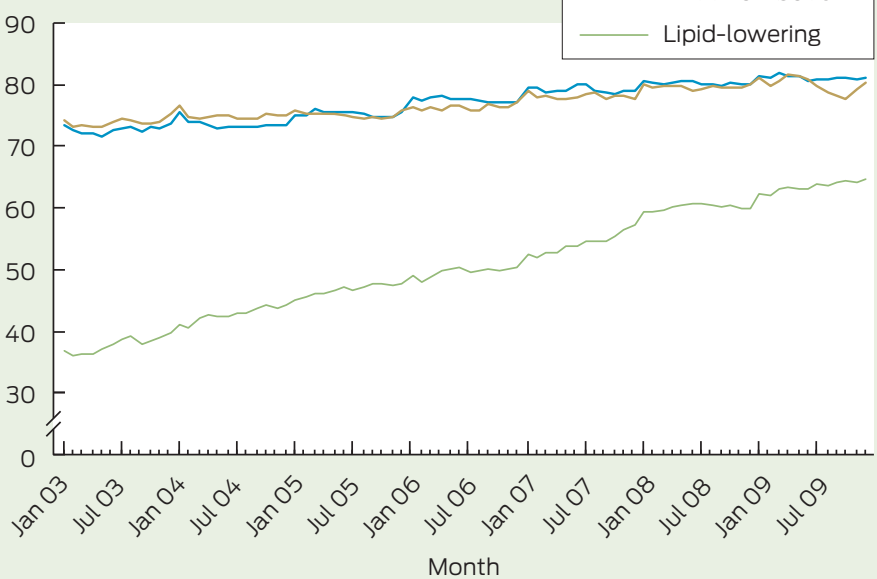

use observed in this study. Strokespecific sections were included in yearly editions of Australia's national formulary (the Australian medicines handbook) and updated versions of Therapeutic guidelines (neurology). Evidence-based stroke prevention and management was also reviewed in Australian prescriber 12 and targeted by National Prescribing Service initiatives. ${ }^{13}$ The study population and their general practitioners would have received information about antithrombotics through the Veterans' Medicines Advice and Therapeutics Education Services (Veterans' MATES) program during the study period. Additional factors likely to have had an impact on the use of lipid-lowering medicines include the publication of a landmark trial14 and changes to eligibility criteria for subsidisation of these medicines through Australia's national pharmaceutical subsidy scheme ${ }^{15}$ during 2006.

Factors influencing the use of secondary stroke prevention medicines in older populations are complex, and may be related to lack of awareness of guideline recommendations, prescriber-related factors (such as concern about the lack of evidence to guide secondary prevention among older patients and potential harms of treatment) or patients' preferences. ${ }^{16}$ Although there may be room for improvement in use of these medicines, our results reflect use among all survivors, as we lacked clinical information necessary to exclude those with treatment contraindications or previous adverse reactions. We do not expect all patients could be dispensed each medicine, as some older patients may be unsuitable for treatment on entering the cohort. For others, treatment priorities may change over time, ${ }^{17}$ and medicines for secondary prevention (such as lipid-lowering therapy) may be withdrawn during the late stages of life, or in those with severe physical impairment or cognitive deficit. ${ }^{18}$ The number of older patients ineligible for treatment may be significant. In a study assessing antithrombotic use by older patients with acute ischaemic stroke, more than one-third were excluded from the analysis, owing to contraindications or refusal of treatment at discharge. ${ }^{19}$ Trends in antithrombotic use observed in our study may be further

\section{Trends in monthly use of combination therapy by patients previously hospitalised with a transient ischaemic attack or ischaemic stroke}

A: Dispensed antihypertensive and antithrombotic medicines

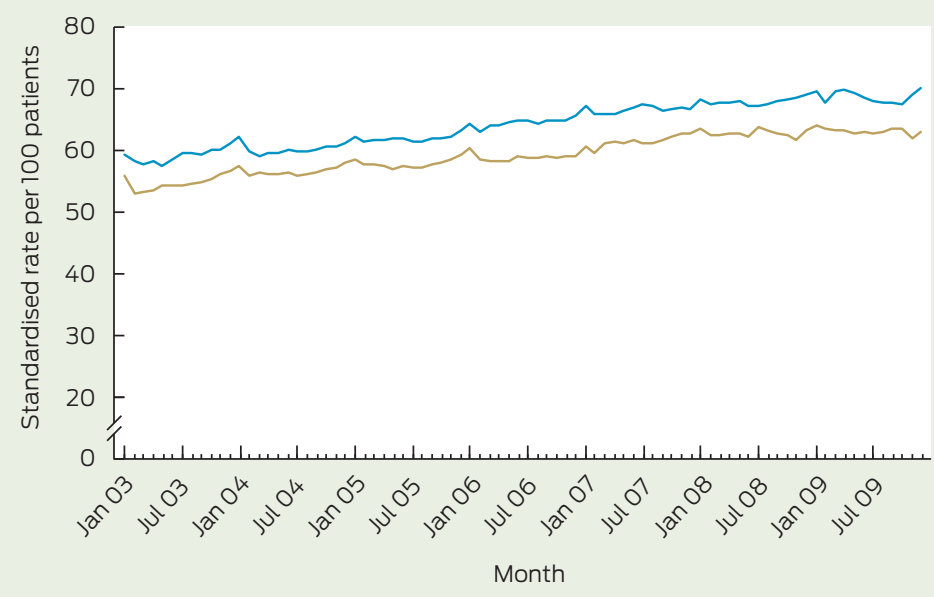

B: Dispensed all three classes of secondary stroke prevention medicines

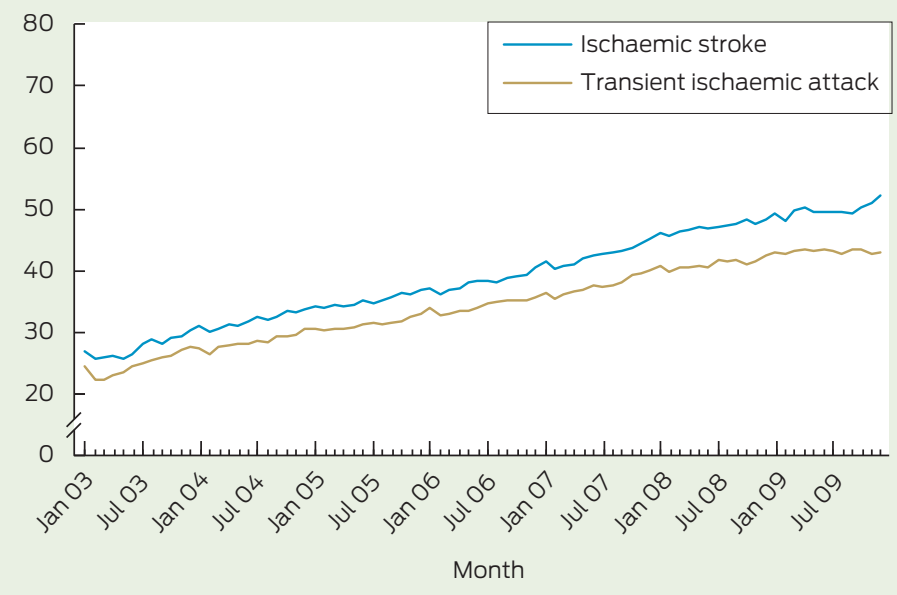


underestimated, as aspirin can be purchased without a prescription in Australia (although patients included in this study had access to subsidised aspirin via prescription).

This study used hospital claims data to determine whether patients had a TIA or ischaemic stroke. To minimise selection bias, patients were selected using primary diagnosis codes and those with an unspecified stroke (ICD10-AM code I64) were not included. There is high adherence to Australian standards for ICD-10-AM coding, ${ }^{20}$ and $95 \%$ of patients with a primary diagnosis code for stroke were correctly coded in a recent Australian audit. ${ }^{21}$

We expect that use of recommended medicines by patients included in this study is indicative of use by older Australians previously hospitalised for TIA or ischaemic stroke. Age-specific comparisons show veterans without a service-related disability and the general Australian population have similar use of pharmaceuticals, hospital services and GP visits. ${ }^{22}$ However, changes in medicine use observed in this study may not be generalisable to patients managed solely in the community setting, and without assessment of clinical records it is not known if treatment targets were attained.

The increased use of secondary stroke prevention medicines shown between 2003 and 2009 in this large cohort of older Australians with a previous TIA or ischaemic stroke is consistent with Australian stroke guideline recommendations and initiatives to support quality use of medicines during the study period.

Acknowledgements: We thank DVA for providing data and reviewing the manuscript before submission.
Competing interests: No relevant disclosures. Received 06 Dec 2013, accepted 13 May 2014.

1 Giles MF, Rothwell PM. Risk of stroke early after transient ischaemic attack: a systematic review and meta-analysis. Lancet Neurol 2007; 6: 1063-1072.

2 Hardie K, Hankey GJ, Jamrozik K, et al. Ten-year risk of first recurrent stroke and disability after first-ever stroke in the Perth Community Stroke Study. Stroke 2004; 35: 731-735.

3 National Stroke Foundation. Clinical guidelines for stroke management 2010. Melbourne: NSF, 2010. http://strokefoundation.com. au/site/media/clinical_guidelines_stroke_ managment_2010_interactive.pdf (accessed May 2014).

4 National Stroke Foundation. National stroke audit. Acute Services Clinical Audit Report 2009. Melbourne: NSF, 2009. http:// strokefoundation.com.au/site/media/ National_stroke_audit_acute_services_clinical audit_report_20091.pdf (accessed Dec 2013).

5 Heeley E, Anderson C, Patel A, et al. Disparities between prescribing of secondary prevention therapies for stroke and coronary artery disease in general practice. Int J Stroke 2012; 7: 649-654.

6 Thrift AG, Kim J, Douzmanian V, et al. Discharge is a critical time to influence 10 -year use of secondary prevention therapies for stroke. Stroke 2014; 45: 539-544.

7 Australian Government Department of Veterans' Affairs. Treatment population statistics. Quarterly report, December 2010. Canberra: DVA, 2010. http://www.dva. gov.au/aboutDVA/Statistics/Documents/ TpopDec2010.pdf (accessed May 2014).

8 Sluggett JK, Caughey GE, Ward MB, et al. Transient ischaemic attack and ischaemic stroke: constructing episodes of care using hospital claims data. BMC Res Notes 2013; 6: 128.

9 Ramsay SE, Whincup PH, Wannamethee SG, et al. Missed opportunities for secondary prevention of cerebrovascular disease in elderly British men from 1999 to 2005: a populationbased study. J Public Health (Oxf) 2007; 29: 251-257.

10 Lee S, Shafe AC, Cowie MR. UK stroke incidence, mortality and cardiovascular risk management 1999-2008: time-trend analysis from the General Practice Research Database. BMJ Open 2011; 1: e000269.

11 Siggaard-Andersen N, Freiberg JJ, Nordestgaard BG. Only a fraction of patients with ischaemic diseases or diabetes are treated to recommended target values for plasma lipids. Dan Med J 2012; 59: A4470.

12 Lindley RI, Landau PB. Early management of acute stroke. Australian Prescriber 2004; 27: 120-123. http://www.australianprescriber.com/ magazine/27/5/120/3 (accessed May 2014).

13 National Prescribing Service. Using antithrombotics wisely in stroke prevention. NPS News 62. Sydney: NPS, 2009. http://www.nps.org.au/_data/ assets/pdf file/0006/67632/news62 antithrombotics_0209.pdf (accessed Dec 2013).

14 Amarenco P, Bogousslavsky J, Callahan A, et al. High-dose atorvastatin after stroke or transient ischemic attack. N Engl J Med 2006; 355: 549-559.

15 Australian Government Department of Health PBS-eligibility criteria for cholesterol lowering medicines. Canberra: Commonwealth of Australia, 2006. http://www.pbs.gov.au/info/ news/2006/09/Eligibility-cholestl-lwringmeds (accessed May 2014).

16 Maraldi C, Lattanzio F, Onder G, et al. Variability in the prescription of cardiovascular medications in older patients: correlates and potential explanations. Drugs Aging 2009; 26 Suppl 1: 41-51.

17 American Geriatrics Society Expert Panel on the Care of Older Adults with Multimorbidity. Guiding principles for the care of older adults with multimorbidity: an approach for clinicians. J Am Geriatr Soc 2012; 60: El-E25.

18 Hilmer S, Gnjidic D. Statins in older adults. Australian Prescriber 2013; 36: 79-82. http://www.australianprescriber.com/ magazine/36/3/79/82 (accessed May 2014).

19 Lichtman JH, Naert L, Allen NB, et al. Use of antithrombotic medications among elderly ischemic stroke patients. Circ Cardiovasc Qual Outcomes 2011; 4: 30-38.

20 Henderson T, Shepheard J, Sundararajan V. Quality of diagnosis and procedure coding in ICD-10 administrative data. Med Care 2006; 44 1011-1019.

21 Marsden DL, Spratt NJ, Walker R, et al. Trends in stroke attack rates and case fatality in the Hunter region, Australia 1996-2008. Cerebrovasc Dis 2010; 30: 500-507.

22 Australian Institute of Health and Welfare. Health care usage and costs: a comparison of veterans and war widows and widowers with the rest of the community. Canberra: AlHW, 2002. (AlHW Cat. No. PHE 42.) http://www.aihw.gov.au/publicationdetail/?id=6442467407 (accessed May 2014). 